\title{
A REVIEW ON THE USE OF POLYETHYLENE TEREPHTHALATE (PET) AS AGGREGATES IN CONCRETE
}

\author{
Tanvir Uddin Chowdhury ${ }^{1}$, Mahmud Amin Mahi², Kazi Azizul Haque ${ }^{3 *}$, Md. Mostafizur \\ Rahman $^{4}$
}

${ }^{1}$ Graduate Scholar,Islamic University of Technology, Board Bazar, Gazipur-1704, Bangladesh

${ }^{2}$ Lecturer, Department of Civil Engineering,Stamford University Bangladesh

${ }^{3}$ Gradute Scholar, Islamic University of Technology, Board Bazar, Gazipur-1704, Bangladesh

${ }^{4}$ Lecturer, Department of Chemical Engineering and Polymer Science, Shahjalal University of Science and Technology (SUST), Sylhet- 3114, Bangladesh, Phone: 880-821-713491, Fax: 880-821-71525

*Correspondence Author: kazinamal@gmail.com

E-mail:atanvir@iut-dhaka.edu,mahmudaminmahi@yahoo.com, mostafizur.cep@gmail.com,

Received: $21^{\text {st }}$ September 2016

Revised:29 $9^{\text {th }}$ April 2018

Accepted: $1^{\text {st }}$ May 2018

DOI: https://doi.org/10.22452/mjs.vol37no2.4

\begin{abstract}
Massive amount of plastic and polymer products are being produced worldwide on a daily basis. Most of these are intended to be recycled, but the reality is quite different. Statistics show that the percentage of recyclable plastic and polymer products that are actually recycled is very insignificant. These plastic products are mostly non-biodegradable. As a result, they persist in the environment as potential pollutants. Hence there have been countless attempts to reuse these plastic products through versatile applications. This paper attempts to compile the studies which explored the reusability of plastic products in structural concrete. The principal focus will be on use of recycled Polyethylene Terephthalate (PET) in structural concrete in various forms. This study concludes that incorporating PET as a supplementary material in different forms has both beneficial and harmful impacts on various fresh and hardened properties of concretes and thus should be considered for comprehensive investigation.
\end{abstract}

Keywords: PET; fresh concrete; concrete composites; supplementary materials; sustainable building material.

\section{INTRODUCTION}

In the present world of consumerism, plastic and polymers have been the prime choice of materials in packaging industries. Between them, for packing purpose the most extensively used material is plastic and 53\% of the products around the world is being packed with plastic. However, plastic is a material which is comparatively lighter than any other material having less weight along with high relative strength for which it is considered as one of the most energy efficient, robust and economic system of 
packaging (Information Sheet Packaging, Aug-2008). According to the United Nations Environmental Programme, global plastic consumption has gone from 5.5 million tons in the 1950 s to 110 million tons in 2009 (United Nations Environment Program, 2009). Recently a business report has revealed that there is an increase in plastic consumption over the last five years. In addition, plastic products are being used increasingly as a replacement of other materials such as wood, paper, metals and glass in various applications. The report predicts a continuous increase in demands for plastics throughout the next five years (Global Plastic Product \& Packaging Manufacturing: Market Research Report, 2013). With the boost in the demand for plastic products worldwide, there is increased concern among the frontline environmental activists regarding their recyclability and reuse. The reasons are quite obvious. Plastics and polymer based compounds are the most widely used packaging materials. Startlingly, packaging represents approximately onethird of municipal waste in the United States (Ackerman, 1997). A study report by a major food manufacturing company revealed that all the materials which have been used for the purpose of packaging has a negative percussion on the environment. The environmental impacts of the production, use and jettison of these materials include the formation of greenhouse gasses, the release of toxins and the scarring of landscape (e.g. mining pits). According to the Institute of Lifecycle Environmental Assessment (ILEA), there are quantifiable environmental costs to the manufacture, use and disposal of packaging materials (ILEA,1992). In addition to that, because plastics have only been produced in a mass scale for around 60 years, their longevity in the environment is still uncertain. There are a variety of plastic among which not a single variety is biodegradable; rather than remarkably tenacious (Andrady, 1994). Therefore, the majority of polymers manufactured today will persist for at least decades or probably centuries. Even though the plastic having the quality of degradation, may be irresistible for a considerable amount of time depending on various local environmental factors, as rates of degradation depend primarily on physical factors; such as, levels of ultraviolet light exposure, oxygen and temperature (Swift, et al., 2004). On the other hand, plastics which are biodegradable craves the existence of suitable micro-organisms. Therefore, degradation rates vary considerably between landfills, terrestrial and marine environments (Kyrikou \& Briassoulis,2007).

\section{Prospect of Recycling}

As most of the plastic products do not metabolize with natural environment easily, they should either be recycled or re-used. On the basis of reuse or recycle plastic can be classified into two categories and they are: Thermoplastics \& thermosetting polymers. Between them thermoplastic have the properties for which it can be reused. As example PET, Polyethylene and Polypropylene are of this kind and they are recyclable. On the other hand, thermosetting polymer is such a classification of plastic which having the reverse properties of thermoplastics. For that reason it cannot be recycled, rather than sometimes uses as a 
material in paint or others named as filler and for that purpose the shape of the thermosetting polymer are decreased; sometimes pulverized into more finer forms (Rebeiz \& Craft, 1995). they are turned into other products. Currently this practice is going on as recycling of this plastic. Thermosetting plastic have a different interlocking between the molecules, termed as cross linked. Unsaturated polyester, epoxy resin is the example of such kind of the polymer. This kind of polymer are used as tires of the varies types of vehicles. The rubber used as tires are also recycled. For the recycle purpose of this plastic, they are crumbled into pieces and by proper procedure. This practice is increasing because of the direction of European Union (EU) about filling of land with waste(1999/31/EC). In that direction the EU has completely banned the filling of land with tire waste (Dvorak\& Kosior, 2009).

Though thermoplastics polymers are potential recyclable materials, global statistics doesn't report satisfactory recycling of these materials in the recent years. For example, in US the plastic bottle is manufactured by PET plastics and their occupancy of the market is 96\% (APPR. 2008). The annual consumption of the beverage bottles manufactured by plastic in America is 34 billion; the percentage of waste is near about $80 \%$ of the total use because of not recycling them. By numerical figure the waste can be represented as per second 877 bottles. In country like Canada, $12 \%$ of the waste plastic bottles are recycled. Some companies of the world are trying to use recycled materials in their productions; like soda bottles. Actually the companies use recycled materials in their productions very little. Of the total production of the wellknown beverage 'Coke'; $2.5 \%$ materials are used which are recycled; this percentage is very low as earlier they used about $25 \%$ of recycled materials (United State National Post-Consumer Plastics Bottle Recycling Report, 2008).

It is very unfortunate that all the plastic bottles used in US; only $6.8 \%$ of them are recycled. The figure for the plastic bottle is not satisfactory, but for the HDPE plastic the percentage is richer considering plastic bottle. The percentage of recycling of the milk jogs and water bottles made with HDPE plastic is nearly $28 \%$ while $12 \%$ of the total plastic bags are reprocessed. However, one of the most used plastic type is PVC plastic. It is widely used in the bottle market of US and UK having a market share of $0.8 \%$ which is less then PET plastic and polypropylene (Bottled Water. (n.d.). Retrieved July 6, 2010; Wastes - Resource Conservation Common Wastes \&Materials - Plastics. (n.d.). Retrieved July 7, 2010]. Most of the cases the plastic products are thrown away. From the perspective of America, yearly waste of PVC plastic is very high; numerically the amount is exceeding 7 billion pounds and the percentage of recycling them is very little; which ranges between $0.1 \%$ to $3 \%$ [Waste Watch information sheet Plastics. (n.d.). Retrieved July 7, 2010].

The usability of PVC has increased worldwide. For chilling purpose, the use of PVC is more than 300 billion pounds; these have been installed 30-40 years before in the constructions. The lives of the used PVC will come to the end it is necessary to be disposed 
[Ranks First in Nation in Percentage of PVC Incinerated; Estimated 17,858 Tons of PVC Burned Annually - National Report on PVC, The Poison Plastic, Describes Looming Waste Crisis and Pervasive Hazards. (2004, December 7). Retrieved July 7, 2010; About PVC - PVC Reports - Executive Summary. (n.d.). Retrieved July 7, 2010]. However, comparing with other sorts of plastic, Polystyrene is the only one type of which the consumption has decreased. The reduction percentage is $9 \%$ for the time period of 1974 to 1999 . The percentage of recycling has also become higher which is very nearer to $30 \%$; peanuts packed with PS are reused other than trashed [Polystyrene and the environment Ease of Disposal. (n.d.). Retrieved July 7, 2010]. As such reuse of these materials would probably be the smartest decision. Figure 1. Shows the picture of recycled plastic materials used in the field.

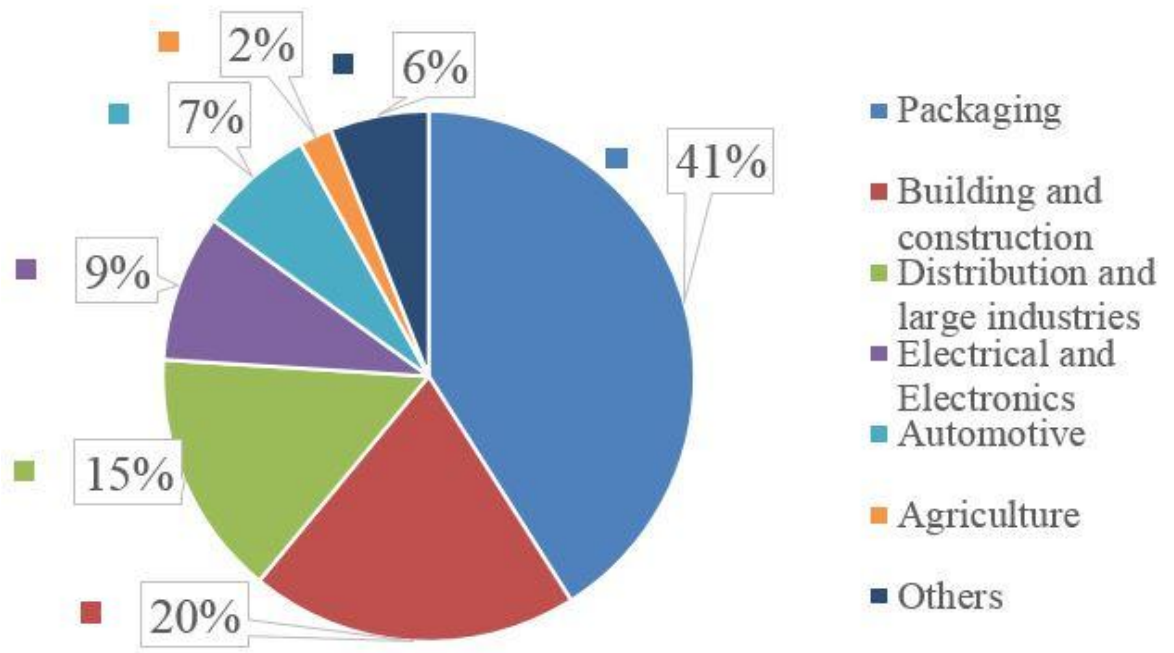

Figure 1: Recycled Plastic Material Used in Different Field (Zoorob \& Suparma, 2000).

In response to these problems, significant amount of researches has been conducted focusing on the reusability of these plastic and polymer wastes. Many has found potential in these hazardous wastes to be used as filler materials in concrete masonry structures. This study attempts to bring a few such researches into light. The principal focus of this paper would be on the studies exploring the potential of using PET in masonry applications in various forms.
Studies regarding other polymer based materials such as HDPE, resins, and waste tyre rubbers would also be covered in brief.

\section{RECYCLING METHODS}

Solid waste can be considered as the main source of material for recycling 
purpose. Present days many productions are going on based on recycling solid waste. Plastic aggregate is one of them, in various experiment it has been a major material. In studies where, plastic bottles were used as aggregates, the help of laboratory is being taken. Because the bottles used in the studies have to be reshaped and the reshaping process in done in the laboratory. To ensure the expected size, the bottles are crumbled in the laboratory mechanically; and then the grinded particles are passed through sieves. Finally, the expected size is obtained. To process the plastic waste to get suitable size; some companies use the help of propeller crushers or blade mills. In some cases the waste treatment plants or the manufacturing organizations of plastic are the source of suitable sized plastic (Akçaözoğlu et al.,2010; Marzouk et al.,2007).

Processing of aggregates varies significantly with respect to their types and sources. For preparation of PET aggregates there are some well-known processes. One such example is established by Saikia and Brito (Saikia, \&Brito,2013); (Saikia \& Brito,2012). In their study they used different types of the aggregates, those were plastic aggregates. There are three different class of plastic aggregate used in their study. Flaky waste PET aggregate with two different size ranges and a pellet-shaped product collected directly from waste PET treatment plant in the form of aggregate for application in concrete. PET waste are grinded mechanically and then the above mentioned properties of aggregate are obtained.
The waste of from the PET are obtained and they are processed. In this process the waste is grinded. The process is a performed through an automated machine and termed as involuntary process. Before after the process the particle are being washed. The washing process is performed by the alkaline solution. For the removal of impurities; the obtained particles are washed in water through centrifugation. Through the treatment process, some impurities like glass, glue are removed. By the grinding of PET waste, some other flakey particles of PET generated which are considered as waste. The size ranges between $10-14 \mathrm{~mm}$. additionally some finer particles are also generated. For removing the finer particles; the de-dusting system is used. Similar process was observed in small scale pet treatment plants in Bangladesh. The comparatively finer PET particles which are the byproducts in this process, is sized between $1 \mathrm{~mm} 4 \mathrm{~mm}$ as observed by the authors.

There are some other processes to modify the wastes. Using high temperature, by automation system, by imbruing in water are some of them. These are the process are adopted primarily for the better attribute of the waste to form superior quality of the aggregate to use as a concrete material. Recently, plastic aggregate has been prepared by one of the authors. The aggregate has prepared in two ways and classified as two types. In that process granulated waste was melted and mixed with powdered river sand with blast furnace slag at $25^{\circ} \mathrm{C}$. after the mixture was prepared, then it cooled down with the sand powder remained and the aggregate of blast furnace slag. Afterwards 
these are sieved with $0.15 \mathrm{~mm}$ sieve(Choi et al.,2009; Choi et al., 2005).

\section{APPLICATION OF RECYCLED PET}

\section{Uses of PET as Aggregate}

A number of studies have been conducted by different authors focusing on issues regarding use of PET in structural conventional and structural-lightweight concrete. These issues include fresh and hardened mechanical properties such as, slump density, compressive strength, tensile strength, flexural strength, elasticity modulus, S-S curve, pulse velocity as well as durability. Other properties of concrete like, shrinkage, water Absorption, water sorptivity, carbonation, $\mathrm{Cl}^{-}$migration, fire resistance, microstructure, thermal properties , Freeze-thaw resistance, etc. has also been covered in some studies.

For example, a study has been conducted about the use of the aggregate obtained from the PET (Bocci et al., 2000). The study relate with the application of the plastic which degrades slowly, harder and never be conjoined with the bitumen (PVC and PET), can be possible to reinstatement of the percentage of the stone aggregate in the composite. The study covered the dynamic characterization of mechanical properties of bituminous concrete mixtures combined with plastics. For observational some experimental procedure has done; including Marshall test, indirect tensile test, static creep test and dynamic test. In this study it has been affirmed that it is possible to avail Refuse Derived Plastic (RDP) to fabricate bituminous concrete in particular hard plastics non-mixable with bitumen, on the condition that PVC and PET are thin milled, of a small size and used in limited quantities (Bocci et al.,2000).

Akçaözoğlu et al., [2010] used Polyethylene terephthalate (PET) bottle granules as a lightweight aggregate which was shredded. They used the water-binder $(\mathrm{w} / \mathrm{b})$ ratio and $\mathrm{PET}-$ binder $(\mathrm{PET} / \mathrm{b})$ ratio 0.45 and 0.50 , respectively in the mixtures and the size of shredded PET granules in the preparation of mortar mixtures were between 0 and $4 \mathrm{~mm}$. For the observation, the prepared sample were sorted out in two classes. Between the two classes of sample one was casted using the PET aggregate alone and in the other both PET and sang aggregate used. Additionally, they used blast-furnace slag as the replacement of cement on mass basis at the replacement ratio of $50 \%$ to reduce the amount of cement used and provide savings. Their investigation shows that, mortar containing only PET aggregate, mortar containing PET and sand aggregate, and mortars modified with slag as cement replacement can be dropped into structural lightweight concrete category in terms of unit weight and strength properties (Akçaözoğlu et al.,2010).

In another study, Mariaenrica (Mariaenrica,2010) substituted in concrete, $5 \%$ by weight of fine aggregate (natural sand) with an equal weight of granular PET aggregates manufactured from the waste unwashed PET bottles (WPET). The author investigated influence on the WPET/concretes as well as reference concretes containing only natural fine 
aggregate, resulting from substitution of WPET to the fine aggregate in concrete through rheological characterization on fresh concrete and mechanical tests at the ages of 28 and 365 days. From the experiments, author found that the WPET concrete would display similar workability characteristics, compressive strength and splitting tensile strength slightly lower that the reference concrete and a moderately higher ductility. In contrast, it has been made non-biodegradable plastic aggregates from polycarbonate (PC) and polyethylene terephthalate (PET) waste (Hannawi et al.,2010). These were used as partial replacement of natural aggregates in mortar with percentage volume fractions of sand $3 \%, 10 \%, 20 \%$ and $50 \%$. Their study defends, it is feasible to reuse polycarbonate and PET waste aggregates materials as partial volume substitutes for natural aggregates in cementitious materials. Though the compressive strength decreased according to their experiments, but they also reported a reduction of the specific weight of the cementitious materials and a significant improvement of their post-peak flexural behavior. Moreover, they found that the calculated flexural toughness factors would increase significantly with increasing volume fraction of PET and polycarbonate aggregates. Additionally, PC and PET plastic aggregates in cementation material would give good energy absorbing materials which would be very interesting for several civil engineering applications like structures subjected to dynamic or impact efforts (Mariaenrica, F., 2010).

Excitingly, in a study (Marzouk et al., 2007) PET has been used as partial and complete substitutes (varying from $2 \%$ to
$100 \%$ ) for sand in concrete composites. The bulk density and mechanical characteristics of the composites produced were evaluated to find out the relationship between mechanical properties and composite microstructure using electron microscopy technique. Their study discovered that substituting sand at a level below $50 \%$ by volume with granulated PET, whose upper granular limit equals $5 \mathrm{~mm}$, affects neither the compressive strength nor the flexural strength of composites, which is somewhat contradictory to other studies such as (Hannawai et al.,2010). However, the study suggested, PET bottles shredded into small particles might be used successfully as sandsubstitution aggregates in cementitious concrete composites. These new composites would appear to offer an attractive low-cost material with consistent properties; moreover, they would help in resolving some of the solid waste problems created by plastics production and in saving energy.

It has been confirmed in another study that addition of shredded PET waste decreases the dry density of polymer mortars, fracture mechanics are altered by shredded PET, material becomes more ductile and shredded PET aggregates produces a composite material with high energy absorbing ability (Reis et al., 2011). The authors used (PET) waste from beverage containers as partial replacement of aggregates in mortar where weight fractions of sand $5 \%, 10 \%, 15 \%$ and $20 \%$ were replaced by the same weight of plastic. They investigated the fracture properties of the obtained composites and a reduction of the specific weight of the polymer mortars but a significant improvement of their post-peak 
flexural behavior was observed (Reis et al.,2010).

In our study, previously, it is found that addition of PET as partial replacement of fine aggregates in mortar reduces compressive strength of the mortar. The study shows that the replacement of $23.3 \%$ fine aggregate with PET in mortar, the compressive strength decreases to $69 \%$ (Rahman et al.,2013).

A unique study has been conducted by Makoto et al. (2001). They studied the physical properties of porous polymer concrete containing recycled plastic aggregates. As their study material, they used PET bottle along with magnet tape highstrength, high-durability epoxy resin as a binder. For the progression of the work, they manufactured the porous polymer concretes by pre-packed concrete method. Besides experimentally investigating physical and mechanical properties of the porous polymer concretes, they also compared them with those of porous polymer concretes made of lightweight aggregate with low density and low water absorption. The authors reported that, the manufactured porous polymer concretes would have a density of less than $1000 \mathrm{~kg} / \mathrm{m} 3$ and a void ratio between 0.27 and 0.40 . It was also concluded that the porous polymer concretes can be used for such applications as planting concretes and filtering materials with resource recycling.

The results obtained in our laboratory differ much from those reported in the literature. Different authors presented the recycled plastic contents in different ways. Results as observed by different authors have been summarized in Table 1 
Table 1: Results observed by Different authors

\begin{tabular}{ll}
\hline Source of Data & Composition and type of plastic aggregate \\
\hline Marzouk et al & $\begin{array}{l}\text { Granulated PET of upper granular limit equals } \\
5 \text { mm,used as partial and complete substitutes } \\
\text { [2007] }\end{array}$ \\
(varying from 2\% to 100\%) for sand in concrete \\
Reis et al.[2011] & $\begin{array}{l}\text { Used (PET) waste from beverage containers as } \\
\text { partial replacement of aggregates in mortar } \\
\text { where weight fractions of sand 5\%, 10\%, 15\% }\end{array}$ \\
and 20\% were replaced by the same weight of \\
plastic
\end{tabular}

Bocci et al.[2000] Used low degradable plastics, hard and nonmixable with bitumen (PVC and PET), as a possible replacement of a portion of the stone aggregate mixture

Kim et al.[2010] PET as short fibersfor fiber volume fractions of $0.5 \%, 0.75 \%$, and $1.0 \%$.

Mariaenrica

[2010]

Hannawi et al. [2010]

Akçaözoğlu et al.[2010]

Rahman et al.[2013]
Substituted in concrete, $5 \%$ by weight of fine granular PET aggregates manufactured from the waste un-washed PET bottles (WPET) and

Non-biodegradable plastic aggregates made from polycarbonate (PC) and polyethylene terephthalate (PET) waste. These were used as partial replacement of natural aggregates in mortar with percentage volume fractions of sand $3 \%, 10 \%, 20 \%$ and $50 \%$

Used PET bottle granules as a lightweight aggregate which was shredded. With waterbinder $(\mathrm{w} / \mathrm{b})$ ratio and PET-binder (PET/b) ratio 0.45 and 0.50 , respectively in the mixtures and the size of shredded PET granules in the and $4 \mathrm{~mm}$

Used PET as partial replacement of fine aggregates in mortar aggregate (natural sand) with an equal weight of compared with an usual reference concrete. preparation of mortar mixtures were between 0
Findings

substituting sand at a level below $50 \%$ by volume with granulated PET, affects neither the compressive strength nor the flexural strength of composites

A reduction of the specific weight of the polymer mortars but a significant improvement of their postpeak flexural behavior was observed.

Addition of shredded PET waste decreases the dry density of polymer mortars, fracture mechanics are altered by shredded PET, material becomes more ductile and shredded PET aggregates produces a composite material with high energy absorbing ability It is possible to use Refuse Derived Plastic (RDP) to manufacture bituminous concrete, in particular hard plastics non-mixable with bitumen, on the condition that PVC and PET are thin milled, of a small size and used in limited quantities

Compressive strength and elastic modulus both decreased as fiber volume fraction increased. Cracking due to drying shrinkage was delayed in the PET fiber reinforced concrete specimens

WPET concrete would display similar workability characteristics, compressive strength and splitting tensile strength slightly lower than the reference concrete and a moderately higher ductility

It is feasible to reuse PC and PET waste aggregates materials as partial volume substitutes for natural aggregates in cementitious materials. The compressive strength decreased, but a reduction of the specific weight of the cementitious materials and a significant improvement of their post-peak flexural behavior was noted. Moreover, flexural toughness factors would increase significantly with increasing volume fraction of PET and PC-aggregates.

Mortar containing only PET aggregate as well as mortar containing PET and sand aggregate can be dropped into structural lightweight concrete category in terms of unit weight and strength properties.

Replacement of $23.3 \%$ fine aggregate with PET in mortar, compressive strength decreases to $69 \%$ 


\section{Effect of curing environment on PET modified concrete}

Among those who worked with curing environment, (Ferreira et al., 2012) did an excellent work. The authors conducted their study on the dominance of curing conditions on the mechanical performance of concrete containing different types of waste plastic aggregate. The aggregates were used as the barter of the natural aggregates as a ratio of $0 \%, 7.5 \%$ and $15 \%$. To evaluate mechanical performance, they created different exposure condition of the curing, the different environment they created can be stated as the laboratory conditions, wet chamber, and outer environment, to represent different environmental exposures to concrete. The key findings of that study are, increasing the ratio of plastic incorporated and its size lead to a fall in compressive and splitting tensile strength as well as modulus of elasticity of concrete. There is improvement in wear resistance to abrasion. However, it was reported that the condition having more moisture content is best for the performance of concrete without plastic.

The sensitivity of concrete with plastic to curing conditions changes with the replacement ratio and depends on the property being studied. The study also concludes that when the percentages of the plastic is more, the different types of the curing environment manifests the better result influencing the properties mostly depends on the bond between the plastic waste aggregates and the cement paste. It was also found that the response of concrete to the incorporation of plastic differs between curing regimes.

Various scholars of various parts of the world have worked on using the plastic in concrete, among the studies, there is a recent study of Silva et al.,(2013) examined that there is significant influence of the curing condition on the concrete where selected plastic is used as a replacement of the aggregate. In that study, they used the concrete in which a certain proportion of the aggregates have been replaced by the plastic aggregate. They used - polyethylene terephthalate (PET) with natural aggregates $0 \%, 7.5 \%$ and $15 \%$. The study included shrinkage, water absorption by immersion, water absorption by capillarity action, carbonation and chloride penetration tests. The outcome of the test indicates that there is a decline in the concrete properties in which plastic aggregate has been used; the cause of declination is in durability, as the conventional concrete is more durable. It also concludes that, when subjected to drier curing regimes, all specimens performed worse. However, it was observed in sensitivity analyses the concrete mixes containing plastic aggregates tends to deteriorate less than those of conventional concrete, when subjected to progressively drier curing regimes.

\section{Use of PET as fiber}

Among all the studies covering PET induced concrete, using PET in fiber form shows the most promising features. A few but excellent work has been done on the field of recycled PET fiber and its application in 
reinforced-concrete. For instance, Ochi et al.,( 2007) studied about the same field and was successful to made a procedure which can be essential to fabricate the concretereinforcing PET fiber from used PET bottles. As reported by the author, using this method, the concrete and PET fibers are easily mixed at a fiber contents as high as $3 \%$. Surprisingly, no toxic gas was generated during the combustion test of the PET fibers. They found that at $1.5 \%$ volumetric fiber content, a bending strength of around 5.3 $\mathrm{MPa}$ can be achieved. One of the most significant findings of the study is that the change of load deflection with respect to the fiber content for concrete with a watercement ratio of $60 \%$ reflects huge addition of ductility when compared to conventional concrete.

A combination of waste materials which doesn't directly include PET but bears no less importance is taken into interest by Siddique et al., (2008) in their review paper on the utilization of waste products in concrete which include discarded tires, plastic, glass, steel, burnt foundry sand, and coal combustion by-products (CCBs). Here the authors emphasized on the effects of recycled plastic on the fresh and hardened properties of concrete. The analyzed effect of recycled and waste plastic, several standard tests like bulk density, air content, workability, and compressive strength, splitting tensile strength, modulus of elasticity, impact resistance, permeability, and abrasion resistance was discussed in the paper. The study concluded, each of these waste products had specific effects on the properties of fresh and hardened concrete.
Different significant studies have been going on regarding the field of the plastic aggregate, among the studies performed, the study performed by Foti is one of the significant and exceptional study on concrete specimens reinforced with fibers which were made from waste (PET) bottles (Foti,2013). As plastic has been used in the experiment, the use of fiber is a must and because of that plastic bottle had used. The fiber used in the experiment had obtained by flinching the bottles. The fiber then used in the mix concrete as aggregate, in some cases the plastic fiber was used as the reinforcement in the experimented specimen as a substitute of the steel bars. The author found interesting results, especially regarding the adherence between PET and concrete, suggesting a possible use of this material in the form of flat or round bars, or networks for structural reinforcement.

Before the successful examination the replaced plastic aggregate the same scholar also performed some research on this field which included a wide range of testing that was there any possible option of using the obtained plastic fibers collected from polyethylene terephthalate (PET) bottles to increase the ductility of the concrete. The PET fibers used in the experiment were collected from the plastic bottles which were considered as the waste products of the society. These waste bottles were cut in " $\mathrm{O}$ " and strip fibers without any costly manufacturing. The author reported that concrete reinforced with Polyethylene Terephthalate (PET) fibers showed higher ductility. The findings of the experimental study recommends that as the plastic which are used in concrete are reused in it that's 
why the plastic should have possess high deformation in the post-cracking phase (Siddique et al.,2008).

A study conducted by using PET as short fibers intends to identify the performance of recycled PET fiberreinforced concrete compared to polypropylene (PP) fiber-reinforced concrete for fiber volume fractions of $0.5 \%, 0.75 \%$, and $1.0 \%$. Standard tests were performed to investigate properties such as compressive strength, elastic modulus, and restrained drying shrinkage strain (Kim et al., 2010). The authors hypothesis was both compressive strength and elastic modulus both decreased with the increase of the fiber volume. Cracking due to drying shrinkage was delayed in the PET fiber reinforced concrete specimens, compared to such cracking in non-reinforced specimens without fiber reinforcement, which indicates crack controlling and bridging characteristics of the recycled PET fibers. The study concludes, structural member performance, ultimate strength and relative ductility of PET fiber reinforced RC beams are significantly larger than those of companion specimens without fiber reinforcement. In addition, a study was conducted by Fraternali et al., (2011) on thermal conductivity, compressive strength, first crack strength and ductility of recycled PET fiber-reinforced concrete (RPETFRC). The study used industrially extruded RPET monofilaments at $1 \%$ volumetric content. The result shows marked increases in thermal resistance and mechanical strengths of RPETFRC over UNRC. The author also concluded that, the addition of RPET fibers to the mix design produces significantly large ductility of concrete. So the author proposed, RPETFRC is competitive over polypropylene-FRC in terms of strength and ductility enhancements.

\section{Use of Recycled of Resin}

Recycling is an eco-friendly as well as useful process in production of various materials like plastic. Apart from the plastic bottles and others sometimes resin is also used in concrete mixing. Nowadays the concept of the production the polyester concrete which is a high performance composite material from recycled PET, has become an age old tradition. Though the idea is relatively old but it is very useful in minimizing the source cost of fabricating good quality of polyester concrete. The good quality polyester concrete can be found by replacing cement with the resins in concrete. polyester concrete products also allow the long-term disposal of PET waste, an important advantage in recycling applications.

Among the earliest studies in this field, it has been found in one study that chemically modified recycled polyethylene terephthalate (PET) plastic waste to produce unsaturated polyester (Rebeiz,1995). The author noted that, if properly formulated, the unsaturated polyester could be mixed with gravel, sand and fly ash to produce good quality polymer concrete. He investigated the time and temperature dependent properties of polymer concrete using an unsaturated polyester resin based on recycled PET which included the effect of age on strength, the effect of temperature on strength and modulus, shrinkage and exothermal expansion and creep. The study found, use of recycled PET could help reduce the cost of polymer concrete products, save energy, and 
could allow the long-term disposal of PET waste. Later on, the author worked on the strength properties and behavior of unreinforced and reinforced polymer concrete using an unsaturated polyester resin based on recycled PET plastic waste. He reported that resins based on recycled pet can be used to produce good quality of polymer concrete for precast applications such as utility components, transportation components, machine bases and building components. The use of recycled pet in polymer concrete helps in reducing the cost of the material, solving some of the solid waste problems posed by plastics and saving energy(Rebeiz 1996). In a more recent work, Rebeiz et al.,(2006) discussed the properties of polymer concrete using resins based on recycled PET are comparable to those polymer concrete $\mathrm{s}$ made from virgin materials. The study found that resins using recycled PET offer the possibility of a lower source cost for forming useful polymer concrete -based products. Also, the recycling of PET in polymer concrete would help alleviate an environmental problem and would save energy. Potential applications for such polymer concrete materials include precast components; repair materials for Portland cement concrete; and bridge, wall, and floor overlays (Rebeiz, 2006).

Among other recent studies, it has been attempted to predict long-term creep using short-term creep and tried to define the characteristics of creep behavior of polymer concrete bound by recycled-polyester resign (Jo et al.,2007), Rebeiz ,1996). In the study as per experimental measure the compressive stress strain ratio were used, as well as the filler content like $\mathrm{CaCO} 3$ and fly-ash were also used. The authors argued that, the difference between the proposed model and the experimental long-term creep compliance was less than about 4\%. It had been reported that in polymer concrete the creep strain in early age in greater than the ordinary concrete. The authors notified that, creep occurs in polymer concrete as the result of molecular movement in the viscoelastic resigns binder. In polymer concrete the creep strain is relatively higher while filler had not added, normally the most used filler material in polymer concrete is $\mathrm{CaCO} 3$ and shows better performance than fly ash. The authors concluded that, the creep values increased with an increase in applied stress, although the values were not proportional to the stress ratio. According to them it is because of the nonlinear viscoelastic behaviors of recycled-PET PC.

Jo et al., (2006) investigated the mechanical properties such as the compressive strength, splitting tensile strength, and flexural strength of polymer concrete using an unsaturated polyester resin based on recycled PET. In the analysis of the experimented result the author concluded on the mechanical properties of polymer concrete. It has been the result of the analysis that the polymer concrete can achieve compressive strength up to 73.7 $\mathrm{MPa}$, flexural strength up to $22.4 \mathrm{MPa}$, splitting tensile strength up to $7.85 \mathrm{MPa}$, and elastic modulus up to $27.9 \mathrm{GPa}$, at 7 days. It has also reported that the polymer concrete which has fabricated from recycled PET can have the mentioned properties. The relationships among the other properties has also been reported by the author. Like there are some relationships which were reported 
to exist between the compressive strength of polymer concrete and other properties (elastic modulus, flexural strength, and splitting tensile strength). The authors concluded that use of recycled PET in polymer concrete helped in reducing the cost of the material, solving some of the solid waste problems posed by plastics, and saving energy.

\section{Tyre Rubber}

A few authors reconnoitered the possibilities of using tyre rubber and PET waste together in concrete. Among the experiment of the concrete it can be displayed as an example of, Pacheco-Torgala et al., (2012) who worked on the performance of the concrete which contains the rubber of tyres and PET waste. It has been explored from their result of the experiment that there is an effect of waste treatment, the size of waste particles and the waste replacement volume on the fresh and hardened properties of concrete. The study recommends those concrete for structures located in areas of severe earthquake risk and the alkaline environment of the cement paste leads to a degradation of PET fibers.

\section{Uses of PET as Binding Materials:}

There are a few who used binding materials produced from PET in their study. For example, Mahdi et al., (2010) used the recycled polyethylene terephthalate (PET) plastic waste by depolymerizing PET through glycolysis to produce unsaturated polyester resin (UPER). The authors used PET to glycol ratio used $1: 1$ and $2: 1$. The initiator promoter combinations taken were Methyl ethyl ketone peroxide (MEKP) and cobalt naphthanate ( $\mathrm{CoNp}$ ) in one group of sets while Benzoyl peroxide (BPO) and N, $\mathrm{N}$-diethyl aniline (NNDA) in other group of sets. Cube compressive test and tensile strength were done. From result of the compressive strength, it has found that there is a certain range of this strength in which it can vary form, for the PM the range is 15 to $28 \mathrm{MPa}$ and for the PC it is 20 to $42 \mathrm{MPa}$. The tensile strength of polymer concrete was either at par or more than the tensile strength of equivalent grade of cement concrete. The authors concluded that, the result of using such materials are very positive.

\section{PROSPECTS OF BANGLADESH AND DIFFICULTIES}

In Bangladesh, huge quantities of waste polymer materials have already been piled up and the quantities are everincreasing. Comparatively, few amount of PET have been recycled and they are being used for less important applications for example, making toys. However, these waste plastics have high potential to be used as partial replacement of conventional fine aggregate.

There are some significant evidences on the use of waste materials in concrete. A report from one of the studies signifies not to use waste materials in concrete as it decreases the compressive strength of the concrete in a noticeable way, non-load bearing applications where compressive strength is not a primary requirement, still 
have immense possibilities. In addition, some studies also reported that using PET as an aggregate substitution yields good insulating properties, which is an added benefit for hot climate countries like Bangladesh. As such further investigation on applicability of this technique is required.

\section{CONCLUSIONS}

It's quite clear from the paper that there has been considerable amount of research works reflecting on how waste PET can be used in concrete mixes in various forms and there are many conclusions to be drawn from these studies. Among them, one very interesting finding is, by substituting in concrete $5 \%$ by weight of fine aggregate (natural sand) with an equal weight of PET aggregates, the Waste-PET concrete would display similar workability characteristics, compressive strength and splitting tensile strength slightly lower that the reference concrete and a moderately higher ductility.

It has been established that mortar, containing only granular PET aggregates (0$4 \mathrm{~mm}$ ), mortar containing PET and sand aggregate, and mortars modified with slag as cement replacement fall into structural lightweight concrete category. The water absorption and shrinkage values of the mortars produced in such compositions also comply with the requirements for standard lightweight concrete. But some reported that substituting sand at a level below $50 \%$ by volume with granulated PET, whose upper granular limit equals $5 \mathrm{~mm}$, affects neither the compressive strength nor the flexural strength of composites. PET bottles shredded into small particles might be used successfully as sand-substitution aggregates in cementitious concrete composites. However, the shrinkage values of the mortars containing PET aggregates are found to be higher than the shrinkage values of the mortars containing PET and sand aggregates. Moreover, when non-biodegradable plastic aggregates made of polycarbonate and (PET) waste are used as partial replacement of natural aggregates in mortar, the compressive strength decreases, but a reduction of the specific weight of the cementitious materials is noticed. Also a significant improvement of their post-peak flexural behavior as well as the calculated flexural toughness factors would increase significantly with increasing volume fraction of PET and polymer concrete -aggregates. It has also been strongly established by several studies that polymer concrete and PET plastic aggregates in cementation material would generate good energy absorbing composites which would offer interesting properties for several civil engineering applications like structures subjected to dynamic or impact efforts.

Though there are some differences in opinion about the fresh and hardened properties of composites containing PET aggregates, it has been anonymously agreed that the use of shredded waste PET granules and GBFS (Granulated Blast Furnace Slag) in mortar would be helpful for the environmental concern. In any case, it appears that using waste PET in concrete and mortar holds great promise in solid waste management but hysterical use of this 
material can severely affect the quality of construction. It is expected that in future, researchers would explore the overall structural performance of these materials in depth. Is this is an actual solution to solid waste problems caused by PET or is it practical? If so, what should be the conventions of applying this material into masonry construction? These questions can only be answered with absolute clarity if scientists and researchers show their interest in an in depth analysis focusing on this themein days to come.

\section{REFERENCES}

Andrady, A.L. (1994). "Assessment of environmental biodegradation of synthetic polymers: Polymer." Journal of Macromolecular Science, Part C: Polymer Reviews, Vol.34, Issue 1, pp.25-76,

APPR.United State National Post-Consumer Plastic Recyclers.Association of Postconsumer plastic Recyclers, (2008).

About PVC - PVC Reports - Executive Summary.(n.d.). Retrieved July 7, 2010, from PVC: The Poison Plastic - The Campaign for Safe, Healthy Consumer Products: http://www.chej.org/BESAFE/pvc/d ocuments/bad_news_exec_sum.htm. Akçaözoğlu, S., Atiş, C.D., and Akçaözoğlu, K. (2010). "An investigation on the use of shredded waste PET bottles as aggregate in lightweight concrete." Waste Management, Vol.30, Issue 2, pp.285-290,
Ackerman. (1997). Available link: http://www.scribd.com/doc/5778153 8/32/Figure-29-Types-of-ChangeAckerman-1997

Bottled Water.(n.d.). Retrieved July 6, 2010, from Container Recycling Institute: http://www.containerrecycling.org/issues/bottledwater.ht $\underline{m}$

Bocci, M., Colagrande,S., and Montepara,A. (2000). "PVC and PET plastics taken from solid urban waste in bituminous concrete." Waste Materials in Construction Wascon, Vol.1, pp.186-195,

Choi, Y.W., Moon, D.J., Kim, Y.J., and Lachemi, M. , (2009). "Characteristics of mortar and concrete containing fine aggregate manufactured from recycled waste polyethylene."Construction and Building Materials, Vol.23, Issue 8, pp.2829-35

Choi,Y.W., Moon, D.J., Chung, J.S., and Cho, S.K. (2005). "Effects of pet waste bottles aggregate on the properties of concrete." CemConcr Res, Vol.35, Issue 4, pp.776-81,

Dvorak, R., and Kosior, E. (2009). "Plastics recycling: challenges and opportunities

doi:10.1098/rstb.2008.0311."

Philosophical Transaction of The Royal Society B Vol.364, Issue 1526, pp.2115-2126,

Ferreira, M., Brito, J.D., Saikia,N. (2012). "Influence of curing conditions on the mechanical performance of concrete containing recycled plastic aggregate." Construction and 
Building Materials, Vol.36, pp.196204,

Foti, D. (2013). "Use of recycled waste pet bottles fibers for the reinforcement of concrete." Composite Structures.Vol.96, pp.396-404,

Foti, D. (2011). "Preliminary analysis of concrete reinforced with waste bottles PET fibers." Construction and Building Materials, Vol.25, Issue 4, pp.1906-1915,

Fraternali, F., Ciancia, V., Chechile, R., Rizzano, G., Feo, L., Incarnato, L. (2011). "Experimental study of the thermo-mechanical properties of recycled PET fiber-reinforced concrete." Composite Structures, Vol.93, Issue 9, pp.2368-2374,

Global Plastic Product \& Packaging Manufacturing: Market Research Report, (2013) Available link: http://www.ibisworld.com/industry/g lobal/global-plastic-productpackaging-manufacturing.html

Hannawi, K., Kamali-Bernard, S., and Prince,W.. (2010). "Physical and mechanical properties of mortars containing PET and PC waste aggregates."Waste Management, Vol.30, Issue 11, pp.2312-2320,

Information Sheet Packaging. Available link: http://www.wastewatch.org.uk/data/f iles/resources/12/Packaging_Aug08-FINAL-CKT.pdf

ILEA. (1992). Available link: http://www.cailaw.org/institute-forlaw-enforcementadministration/about-us/ourhistory.html
Jo, B.W., Tae, G.H., and Kim, C.H. (2007). "Uniaxial creep behavior and prediction of recycled-PET polymer concrete."Construction and Building Materials, Vol.21, Issue 7, pp.15521559 ,

Jo, B.W., Park, S.K., and Kim, C.H. (2006). "Mechanical Properties of Polyester Polymer Concrete Using Recycled Polyethylene Terephthalate."ACI Structural Journal, http://www.highbeam.com/doc/1P31268540071.html

Kyrikou, I., Briassoulis, D. (2007). "Biodegradation of Agricultural Plastic Films: A Critical Review." Journal of Polymers and the Environment, Vol.15, Issue 3, pp.125-150,

Kim, S.B., Yi, N.H., Kim, H.Y., Kim, J.H.J., and Song, Y.C. (2010). "Material and structural performance evaluation of recycled PET fiber reinforced concrete."Cement and Concrete Composites, Vol.32, Issue 3, pp.232-240,

Marzouk, O.Y., Dheilly, R.M., and Queneudec,M. (2007). "Valorisation of post-consumer plastic waste in cementitious concrete composites." Waste Management, Vol.27, pp.310 318 ,

Mariaenrica, F. (2010). "Recycling of PET bottles as fine aggregate in concrete." Waste Management, Vol.30, pp.1101-1106,

Makoto, K., Hidenobu,T., and Satoru, M. (2001). "Physical properties of porous polymer concrete using recycled plastic aggregates." JCA 
Proceedings of Cement \& Concrete (Japan Cement Association), Vol.55, pp.645-650,

Mahdi, F., Abbas, H., Khan, A. A. (2010). "Strength characteristics of polymer mortar and concrete using different compositions of resins derived from post-consumer PET bottles." Construction and Building Materials, Vol.24, Issue 1, pp.25-36,

Ochi, T., Okubo, S., and Fukui, K. (2007). "Development of recycled PET fiber and its application as concretereinforcing fiber."Cement and Concrete Composites, Vol.29, Issue 6, pp.448-455,

Polystyrene and the environment - Ease of Disposal. (n.d.). Retrieved July 7, 2010, from American Chemistry Council:

http://www.americanchemistry.com/ s_plastics/sec_pfpg.asp?CID $=1434 \&$ DID=5226Connecticut

Pacheco-Torgala, F., Dingb, Y., Jalalia, S. (2012). "Properties and durability of concrete containing polymeric wastes (tyre rubber and polyethylene terephthalate bottles): An overview." Construction and Building Materials, Vol.30, pp.714-724,

Rebeiz, K.S., and Craft, A.P. (1995). "Plastic waste management in construction: technological and institutional issues." Resources, Conservation and Recycling, Vol.15, Issue 3-4, pp.245257 ,

Ranks First in Nation in Percentage of PVC Incinerated; Estimated 17,858 Tons of PVC Burned Annually - National Report on PVC, The Poison Plastic,
Describes Looming Waste Crisis and Pervasive Hazards. (2004, December 7). Retrieved July 7, 2010, from Connecticut Coalition for Environmental Justice Concerned about Health Impacts from Incinerators in Connecticut: http://www.environmentaljustice.org/PVC_Press_Release.htm

Rebeiz, K.S. (1995). "Time-temperature properties of polymer concrete using recycled PET." Cement and Concrete Composites, Vol.17, Issue 2, pp. 119 124 ,

Rebeiz, K.S., (2006). Fowler. D.W., and Paul, D.R. "Recycling Plastics in Polymer Concrete Systems for Engineering Applications." PolymerPlastics Technology and Engineering, Vol.30, Issue 8, pp.809825 ,

Rebeiz, K.S. (1996). "Precast use of polymer concrete using unsaturated polyester resin based on recycled PET waste." Construction and Building Materials, Vol.10, Issue 3, pp.215-220,

Reis, J.M.L., Chianelli-Junior, R., Cardoso, J.L., and Marinho, F.J.V. (2011). "Effect of recycled PET in the fracture mechanics of polymer mortar." Construction and Building Materials, Vol.25, Issue 6, pp.27992804,

Rahman, M.M., Mahi, M.A., and Chowdhury, T.U. (2013). "Utilization of waste PET bottles as aggregate in masonry mortar."International Journal of Engineering Research \& Technology 
(IJERT), Vol.2, Issue 11, pp.10301035 ,

Swift, G. and Wiles, D. M. (2004). "Degradable polymers and plastics in landfill sites."Encyclopedia Polymer Science and Technology, Vol.9, pp.40-51,

Saikia, N., and Brito, J.D. (2013). "Waste polyethylene terephthalate as an aggregate in concrete."Mat. Res. [online], Vol.16, Issue 2, pp.341-350,

Saikia,N., and Brito, J.D. (2012). "Use of plastic waste as aggregate in cement mortar and concrete." Construction and Building Materials, Vol.34, pp.385-401,

Silva, R.V., Brito, J.D., and Saikia, N. (2013). "Influence of curing conditions on the durability-related performance of concrete made with selected plastic waste aggregates."Cement and Concrete Composites, Vol.35, Issue 1, pp.2331 ,

Siddique, R., Khatib, J., and Kaur, I. (2008). "Use of recycled plastic in concrete: A review." Waste Management, Vol.8, Issue 10, pp.1835-1852,

United Nations Environment Program (2009), Converting waste Plastics into a resource, Industry and
Economics International

Environmental Technology Centre, Osaka/Shi, 1-69.

United State National Post-Consumer Plastics Bottle Recycling Report. (2008). Retrieved July 6, 2010, from Association of Postconsumer Plastic Recyclers:

http://www.americanchemistry.com/s_plasti cs/sec_content.asp?CID=1593\&DID $=10383$

Waste Watch information sheet - Plastics. (n.d.). Retrieved July 7, 2010, from Waste Watch: http://www.wasteonline.org.uk/resou rces/InformationSheets/Plastics.pdf

Wastes - Resource Conservation - Common Wastes \&Materials - Plastics.(n.d.). Retrieved July 7, 2010, from US Environmental Protection Agency: http://www.epa.gov/osw/conserve/m aterials/plastics.htm

Zoorob SE and Suparma LB. (2000) "Laboratory design and investigation of the properties of continuously graded Asphalt concrete containing recycled plastics aggregate replacement (plastiphalt)."Cement and concrete composite, Vol.22, pp. $233-242$ 